\title{
EDF R\&D Industrial flow metering test facility: main past achievements and innovative plans for the future
}

\author{
Emmanuel Thibert ${ }^{1, *}$, José Veau ${ }^{1}$ \\ ${ }^{1}$ EDF R\&D, 6 quai WATIER, BP49, 78401 Chatou Cedex, France
}

\begin{abstract}
Electricité de France Research and Development Division (aka EDF R\&D) has been investigated liquid flow meters metrological behavior for 20 years on EVEREST test bench. Experimental studies once focused on simple calibration tests on usual or innovative flow meters with high upstream straight length pipes have turned into sensors uncertainty characterizations campaigns under real industrial installation conditions. In order to enhance these studies, EDF R\&D has come to the conclusion that, in many cases, accurate flow metering uncertainty calculations need comprehensive velocity profile understanding. This key feature can be achieved by mixing CFD results and experimental data. With regard to the latter point, upgrading the EVEREST test bench has become mandatory. Consequently, future EDF R\&D flow metering test bench will aim at not only performing flow calibration tests but also at characterizing real liquid velocity fields for industrial pipe flow configurations. This upgrade has recently been accepted and is currently in progress. Renovation works and technological improvements will hopefully be achieved in 2018 .
\end{abstract}

\section{Introduction}

EDF (the French Electricity Generation company) operates 58 "Pressurized Water Reactor type" nuclear units in France (PWR). In these particular power plants, flow monitoring is essential not only for safety reasons but also for economical ones. For instance, accurate measurement of feedwater flow in PWR plants is necessary to quantify the turbine cycle heat rate of the plant, which is a major component of the overall plant efficiency.

Twenty years ago, EDF appointed its Research and Development Division to carry out experimental tests on usual or innovative flow meters for evaluating their metrological performance. These tests aimed at assessing flow meters metrological behavior in a semi real industrial conditions prior to a potential PWR on-site installations. EDF R\&D consequently designed a specific test bench for this mission.

The basic design concept of EVEREST has consequently two objectives: one is to duplicate the behavior of an industrial liquid pipe flow process as closely as possible, and the second is to monitor an accurate and steady flow metering reference.

\section{Description of EVEREST facility}

\subsection{Design specifications}

EVEREST facility was built at Chatou (France) in 1997. The test facility is a closed loop with a liquid flow rate regulation. Fluid is clean tap water.

Table 1. Overview of the design specification of EVEREST test facility.

\begin{tabular}{|c|c|}
\hline Type & Closed regulated loop \\
\hline $\begin{array}{c}\text { Flow meter } \\
\text { reference }\end{array}$ & Master meters method \\
\hline $\begin{array}{c}\text { Test section pipe } \\
\text { size }\end{array}$ & From DN50 up to DN350 \\
\hline $\begin{array}{c}\text { Pipe compositions } \\
\text { Medium }\end{array}$ & $\begin{array}{c}\text { Stainless steel for test section, black } \\
\text { steel otherwise }\end{array}$ \\
\hline $\begin{array}{c}\text { Master meters } \\
\text { traceability }\end{array}$ & $\begin{array}{c}\text { French national reference standard } \\
\text { (COFRAC calibration) }\end{array}$ \\
\hline Pressure range & From 3 up to 7 relative bar \\
\hline $\begin{array}{c}\text { Fluid temperature } \\
\text { range }\end{array}$ & $\begin{array}{c}\text { From } 20^{\circ} \mathrm{C} \text { up to } 50^{\circ} \mathrm{C} \text { (freely } \\
\text { adjustable) }\end{array}$ \\
\hline $\begin{array}{c}\text { Environment } \\
\text { Temperature }\end{array}$ & $\begin{array}{c}\text { minimum and maximum ambient } \\
\text { temperature are } 15^{\circ} \mathrm{C} \text { and } 35^{\circ} \mathrm{C} \\
\text { respectively }\end{array}$ \\
\hline $\begin{array}{c}\text { Flow metering } \\
\text { uncertainty }\end{array}$ & $\begin{array}{c}\text { from } 0.36^{\circ} \% \text { up to } 0.49^{\circ} \% \text {, depending } \\
\text { of tested flow rate }\end{array}$ \\
\hline
\end{tabular}

\footnotetext{
* Corresponding author: emmanuel.thibert@edf.fr
} 
Table 1 shows the design specifications for EVEREST. The test bench provides a steady water stream from $4.10^{4}$ up to $1.10^{6}$ Reynolds number. Depending on the test section geometrical configuration, flow range generally goes from $30 \mathrm{~m}^{3} \cdot \mathrm{h}^{-1}$ up to $1100 \mathrm{~m}^{3} \cdot \mathrm{h}^{-1}$. Reference volume flow uncertainty goes from $0.36 \%$ up to $0.49 \%$, depending of the tested flow rate [1].

\subsection{Design details}

The major characteristics of EVEREST loop are: -Generation of a steady liquid flow rate for test/calibration purposes,

-Avoidance of air bubbles in the test/reference section pipe flow during a test,

-Temperature and pressure regulation thanks to the heat exchanger and the pressurizer,

-Significant reduction of swirls by installing a Gallagher flow conditioner [2] at the upstream of the reference section,

-High upstream and downstream straight lengths for reference section,

-Use of four different master meters to decrease uncertainty all over the loop flow rate rangeability,

-Use of two "drift detection" ultrasonic flowmeters; large test area $\left(27 \times 5 \mathrm{~m}^{2}\right)$ where several real process mock-ups can be integrated for testing purposes.

Table 2. EVEREST reference meters specifications.

\begin{tabular}{|c|c|c|c|}
\hline \multirow{2}{*}{$\begin{array}{c}\text { Flow rate } \\
\left(\mathbf{m}^{3} \cdot \mathbf{h}^{-1}\right)\end{array}$} & \multicolumn{3}{|c|}{ Reference master meters } \\
\cline { 2 - 4 } & Type & $\begin{array}{c}\text { Ref. } \\
\text { section } \\
\text { pipe } \\
\text { diameter }\end{array}$ & $\begin{array}{c}\text { Volumic } \\
\text { flow } \\
\text { uncertainty } \\
( \pm \mathbf{2} \boldsymbol{\sigma})\end{array}$ \\
\hline $5-150 \mathrm{~m}^{3} \cdot \mathrm{h}^{-1}$ & Coriolis & DN 80 & $0,49 \%$ \\
\hline $150-300 \mathrm{~m}^{3} \cdot \mathrm{h}^{-1}$ & $\begin{array}{c}\text { Electro- } \\
\text { magnetic }\end{array}$ & DN 100 & $0,36 \%$ \\
\hline $300-600 \mathrm{~m}^{3} \cdot \mathrm{h}^{-1}$ & $\begin{array}{c}\text { Electro- } \\
\text { magnetic }\end{array}$ & DN 150 & $0,36 \%$ \\
\hline $600-1100 \mathrm{~m}^{3} \cdot \mathrm{h}^{-}$ & $\begin{array}{c}\text { Electro- } \\
\text { magnetic }\end{array}$ & DN 200 & $0,39 \%$ \\
\hline
\end{tabular}

\subsection{EVEREST layout}

As shown in Figure 1, EVEREST consists in three parts. The first part is the flow metering reference section. In this section are installed the four master meters of the test bench and the two "drift detection" ultrasonic flowmeters. Three electromagnetic meters has been implemented as reference meters. This choice has the advantage of using each meters in their nominal rangeabilities and consequently increasing their accuracy. These meters are used to collect reference flow rates from $150 \mathrm{~m}^{3} \cdot \mathrm{h}^{-1}$ up to $1100 \mathrm{~m}^{3} \cdot \mathrm{h}^{-1}$. Electromagnetic master meters have been installed in the reference section with high upstream and downstream straight lengths (superior to 20 hydraulic diameter aka $D_{H}$ ).

Reference low flow rate (i.e. inferior to $150 \mathrm{~m}^{3} \cdot \mathrm{h}^{-1}$ ) is elaborated thanks to a Coriolis meter. Metrological characterization of the reference meters are detailed in table 2. The calibration cycle of the reference meters is currently one year.

In order to monitor and to detect any reference sensors drift between two annual calibrations, two multipath ultrasonic meters have been installed in the upstream of the reference section. This technology has been chosen for various reasons. Firstly, the technology is different from electromagnetic instrument thus it prevents ultrasonic devices from being subject to common-mode failure risks. Secondly, they don't produce additional pressure losses in the upstream flow pipe and don't interfere with the facility hydraulic operating. And finally, repeatability and reproducibility of ultrasonic meters are reportedly excellent. They consequently constitute a good way to monitor long-term stability issues.

Usual experimental tests are carried out on steady flow rate. At the beginning of a test, bench operator selects the flow rate on the monitoring screen, then the bench control unit system select automatically the appropriate test track and consequently the corresponding master meter.

The second part is the operation section. It includes the circulation pomp, the regulation valves, the pressure regulation unit (pressurizer) and the heat exchanger. EVEREST pump is a constant-speed centrifugal pump. Thanks to regulation valves, it allows a flow rate regulation from $30 \mathrm{~m}^{3} \cdot \mathrm{h}^{-1}$ up to $1100 \mathrm{~m}^{3} \cdot \mathrm{h}^{-1}$. Total Dynamic Head (TDH) is 3 bar. Pressurizer stabilizes the test section water pressure between two and three bar. Wasted energy due to pump inefficiency is converted into heat which is absorbed by the pumped liquid. Due to EVEREST loop configuration, this phenomenon typically increases fluid temperature in the test section by $10^{\circ} \mathrm{C}$ per hour. A heat exchanger has therefore been installed and regulates fluid temperature from $20^{\circ} \mathrm{C}$ up to $50^{\circ} \mathrm{C}$ according to the desired test conditions. Cold fluid in the heat exchanger comes from Seine river.

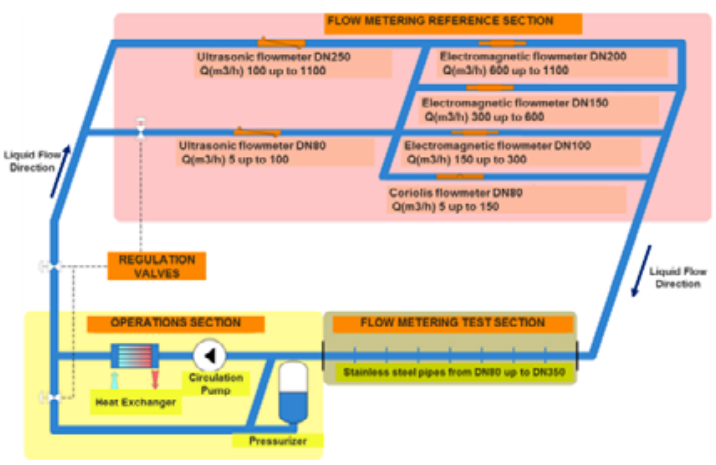

Fig. 1. EVEREST test facility layout.

The last but not least section is the flow metering test section. This inner room section constitutes an available space with a length of $27 \mathrm{~m}$ length and a width of $5 \mathrm{~m}$ width with a high ceiling of $5 \mathrm{~m}$. This test section was initially designed to perform calibration tests on innovative industrial flow meters. Tested devices are generally mounted on stainless steel pipes and can be invasive as well as non-invasive according to the sensor 
technology. However, EVEREST test section is currently a multi-purpose test area which allows to recreate numerous Nuclear Power Plant (NPP) industrial pipeworks or to install a reduced scale mock-up of typical NPP components for metrological purpose. This flexibility allows EDF R\&D to investigate the real installation conditions impacts on industrial flowmeters accuracy: orifice plate installation with no ISO5167-2 required upstream and/or downstream straight lengths of piping [3], ultrasonic flow metering systems under an asymmetric flow profile, pressure fields and velocity profile in the elbow taps at the outlet of a steam generator.

\section{Main past EVEREST experimental achievements}

EVEREST started operating in 1997. At the beginning, main experimental tests were just calibration campaigns on industrial flow meters. These campaigns were generally carried out with simple flow configuration. Generally, tested device was installed on pipe with a high upstream straight length. Such an investigation aimed at assessing the operability of a metering system in a semi-industrial environment (as EVEREST is able to provide it) prior to its utilization on a real industrial process.

In the past 20 years, these feasibility tests were focused mainly on non-invasive flow metering technologies, especially ultrasonic ones. Tests purpose was to quantify the device accuracy. The significant investigations were influence of acoustic couplant (gel, grease or solid for high temperature installation), clampon waveguide (also for high temperature fluid process, pipe material, ultrasonic technology (transit time, crosscorrelation) and asymmetric flow profile influence on meters metrological performances.

A particular experimental campaign can be highlighted here which aimed at finding out if usual ultrasonic transducers were able to accurately measure a flow rate on DN350 composite pipe [4]. These filament wound pipes were manufactured of vinylester resin and glass fiber rovings. This particular material can be found for NPP with river water cooling system.

EDF R\&D tested two clamp-on transit time ultrasonic flowmeters which came from two manufacturers. They are subsequently quoted as device $\mathrm{A}$ and device B. US transducers from device B were more recent than US transducers from device A. These apparatus (transducers + electronics) were not specifically designed for a composite pipe utilization. Transducers frequency is $1 \mathrm{Mhz}$.

These non-invasive devices were located after $33 D_{H}$ straight lengths pipe which provided quasi-calibration conditions. First calibration runs were performed with portable ultrasonic flowmeters installed on black steel pipe. Then a second run has been performed by replacing a $20 D_{H}$ length black steel pipe with a $20 D_{H}$ length composite pipe (cf. figure 2). Two mounting methods have been tested: V-mount and direct-mount (cf. figure
3) with similar results. Direct-mount flow rate is commonly calculated with equation 1 .

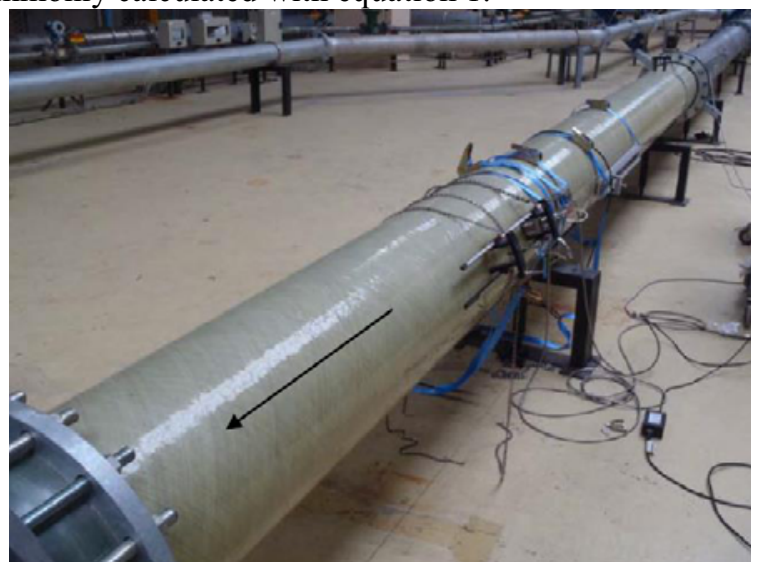

Fig. 2. Clamp-on ultrasonic meter installation on DN350 composite pipe (test section of EVEREST loop).

$$
Q_{v}=\frac{1}{K_{h}} \times \frac{\pi D_{i}^{2}}{4} \times \frac{L}{2 \times \cos (\alpha)} \times \frac{T_{A B}-T_{B A}}{T_{A B} \times T_{B A}}
$$

$T_{A B}$ is the transit time from $\mathrm{A}$ to $\mathrm{B}, T_{B A}$ is the transit time from $\mathrm{B}$ to $\mathrm{A}, L$ is the distance between $\mathrm{A}$ and $\mathrm{B}, D_{i}$ is the inner pipe diameter, $\alpha$ is the fluid penetration angle of the ultrasonic wave, $K_{h}$ is the correction factor.

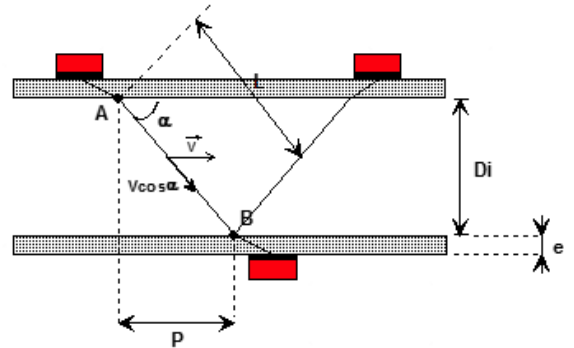

Fig. 3. V-mount and direct-mount method for tested noninvasive ultrasonic flow meters.

The flow profile correction factor value, $K_{h}$, was provided by manufacturers, for turbulent flow conditions [5]. Due to Reynolds number calculation, flow was turbulent.

The two runs results are detailed in Table 3 . Repeatability and reproducibility tests have been also carried out in order to estimate portable ultrasonic device uncertainties. Global uncertainly was around 3\% (95\% confidence level).

Table 3. Bias of ultrasonic clamp-on flow measurements.

\begin{tabular}{|c|c|c|c|}
\hline $\begin{array}{c}\text { Reference } \\
\text { Flow rate } \\
\left(\mathbf{m}^{3} \cdot \mathbf{h}^{-1} \mathbf{)}\right.\end{array}$ & \multirow{2}{*}{$\begin{array}{c}\text { Installation } \\
\text { conditions }\end{array}$} & \multicolumn{2}{|c|}{$\begin{array}{c}\text { Systematic error } \\
\text { (\% of measured value) }\end{array}$} \\
\cline { 3 - 4 } & & Device A & Device $\mathbf{B}$ \\
\hline \multirow{2}{*}{$1050 \mathrm{~m}^{3} \cdot \mathrm{h}^{-1}$} & Black steel pipe & $-0.1 \%$ & $-0.1 \%$ \\
\cline { 2 - 4 } & Composite pipe & $-5.5 \%$ & $-1.5 \%$ \\
\hline
\end{tabular}

Main results showed a discrepancy between steel pipe mounting flow measurement and composite mounting one. Recent transducers were significantly better than old ones, which was not surprising for significant signal processing progress have been done by manufacturers for this kind of sensor in the past years. 
EVEREST tests pointed out the fact that device B measuring system was able to perform an accurate flow measurement even if usual transducers are mounted on composite pipe. This study allowed EDF to install such a non invasive device on NPP composite pipes to monitor cold water flow with high upstream straight length.

Besides flow metering system tests under usual conditions, EVEREST also allows to assess flowmeter accuracy under real industrial configurations. This experimental activity aims at testing devices as they are implemented in NPP. Main purposes are to evaluate/calculate the accuracy of the meters under actual conditions. Due to installations effects, this accuracy can be beyond manufacturer technical specifications or international standards. Accuracy may be then uncalculated or too conservative to match process requirements.

These tests require to recreate as closely as possible, in the EVEREST test section, the exact pipes configurations and the exact device installation in order to validate, on test bench, actual "on site" metrological behavior of the flowmeter.

Prior to tests, EDF R\&D usually investigates some meter accuracy influence factors, quantities which obviously depends of meter technology. Then, NPP pipe installations configurations are built in the test section in order to monitor such influences. Similitudes, especially Reynolds number, are whenever possible respected. However, specific tests at 1:1 scale can be performed outside actual process Reynolds range if pipe installation are the most relevant influence factor to be investigated (such a case generally occurs with non-invasive "clampon" flowmeters).

These "semi-real installation conditions" tests are mainly performed with differential pressure flow meter and orifice plate in particular. Those differential systems represent indeed around $80 \%$ of NPP flowmeters installed park. Measurement of fluid flow principle, mostly used in nuclear power plant, is by means of differential system.

EDF R\&D has performed many tests on orifice plates to estimate influence quantities for flow measurements. Some of these tests were conducted on EVEREST. Influence of upstream straight length on flowmeter accuracy have been particularly investigated. One of the most unusual performed campaign was focused on upstream pipe roughness impact on orifice plate accuracy [6]. These tests aimed at evaluating if the upstream pipe roughness can be significant on pressure differential device flow rate uncertainty.

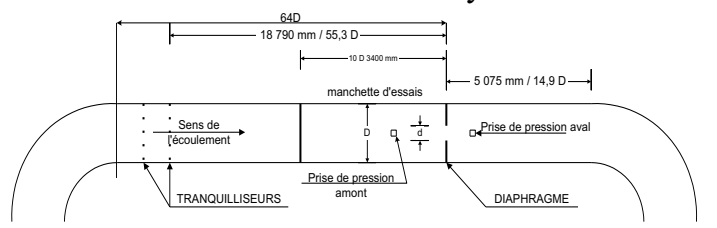

Fig. 4. Pipe roughness tests configuration for orifice plate flow measurement.

The mass flow rate generated by orifice plate, Qm, can be determined using Equation (2):

$$
Q_{\mathrm{m}}=\frac{C}{\sqrt{1-\beta^{4}}} \times \frac{\pi}{4} \times \varepsilon \times d^{2} \times \sqrt{2 \Delta p \rho}
$$

where $\Delta p$ is the difference between the (static) pressures measured at the wall pressure tappings, $\beta$ is the ratio of the diameter of the orifice or throat of the orifice plate to the internal diameter of the measuring pipe upstream of the device, $C$ is the coefficient, defined for an incompressible fluid flow, which relates the actual flowrate to the theoretical flowrate through the orifice plate, $\varepsilon$ is the coefficient used to take into account the compressibility of the fluid, $\rho$ is the density of the fluid and $d$ is the diameter of orifice under working conditions.

To achieve this purpose, a $10 D_{H}$ straight flange with specific controlled roughness has been implemented (cf. figure 4$)$ at the upstream of an orifice plate $(\beta=0.65)$. Installation conditions of the pressure differential devices are in concordance with the ISO5167-2 required straight lengths. Inner diameter was $340 \mathrm{~mm}$. Tested flow rates were performed at four different flow rates (cf. figure 7). Reynolds number range of the flow went from $0.610^{6}$ up to $1.210^{6}$.

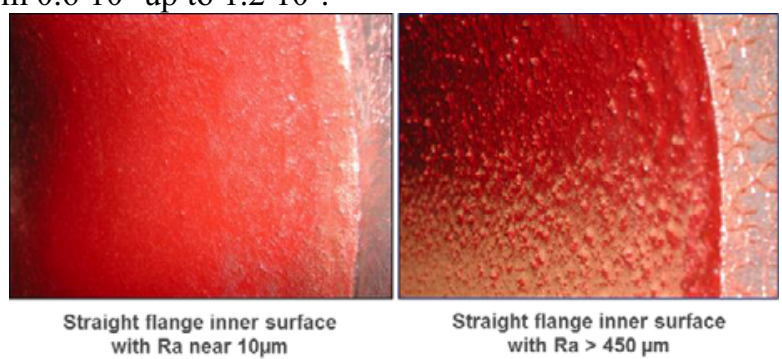

Fig. 5. Upstream pipe roughness influence on orifice plate flow rate accuracy.

Six types of roughness have been investigated, from $\mathrm{Ra}=4 \mu \mathrm{m}$ (brand new stainless steel pipe) up to $\mathrm{Ra}>450 \mu \mathrm{m}$ (dirty pipe), with Ra defined as arithmetical mean deviation of the roughness profile of the inner pipe. To meet the ISO 5167-2 requirements, maximum value of pipe internal roughness for the tested configurations must be $\mathrm{Ra}=27 \mu \mathrm{m}$ (for maximum performed flow rate experiment). Besides the clean pipe, specific roughness pipe have been achieved by coating the pipe inner surface with a sand and red resin mixture (cf. figure 5).

Orifice plate discharge coefficient and its related uncertainty are calculated thanks to ISO 5167-2 formula. Orifice plate flow rate is compared to EVEREST reference flow rate (cf. figure 6). Dotted lines on figure 6 represent the uncertainty of orifice plate flow measurement (95\% confidence level). This value is determined without taking into account the influence of roughness. 


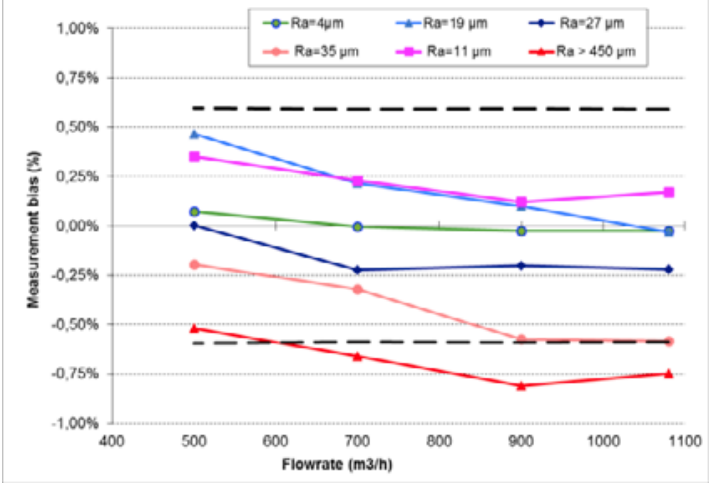

Fig. 6. Upstream pipe roughness influence on orifice plate flow measurement.

EVEREST experimental campaign conclusion was that upstream pipe roughness seemed to have a quite low influence on orifice plate accuracy for the tested configuration. For low or usual roughness pipe values, no tendency can be pointed out for measurement bias were inside the global uncertainty interval (cf. figure 6). Nevertheless, high roughness pipe apparently leads to an underestimation of an orifice plate flow rate.

The last example points out the main advantages of EVEREST test bench. The facility indeed allows to test specific installations conditions. EDF R\&D went further by proposing to recreate specific pipe configurations in order to best estimate industrial flowmeters accuracy under realistic conditions. This tendency generally leads to create mock-ups in order to generate the same flow conditions which can occur on site. These models can be a series of fittings at the upstream of the tested flow meter (succession of $90^{\circ}$ elbow, two $90^{\circ}$ bends in any plane, Single $90^{\circ}$ tee with or without an extension, concentric reducer or expander can be found in NPP process and then can be set up on EVEREST), or specific industrial device (pomp, butterfly valve, needle valve).

One example of this particular investigation can be highlighted here. Main subject was to accurately measure a liquid flow rate thanks to a $40^{\circ}$ pipe elbow. The overall objective of the study was to use an existing NPP elbow taps at the outlet of the steam generator to measure accurately and absolutely the reactor coolant system (RCS) flow continuously and independently of the current method (based on temperature measurements). For safety reasons, RCS flows in nuclear power plants have indeed to be maintained between a high and a low limit. Having two independent methods to characterize this flow can thus be interesting for plant operators [7]. (3):

Volume flow rate can be calculated with equation

$$
Q_{v}=K \times D^{3 / 2} \times R_{c}^{1 / 2} \times \sqrt{\frac{\Delta p}{\rho}}
$$

where $R_{c}$ is the radius of curvature of the elbow [m], $\rho$ is the density of the fluid $\left[\mathrm{kg} \cdot \mathrm{m}^{-3}\right], K$ is the flow coefficient of elbow tap, $D$ is the diameter of the pipe [m], $\Delta p$ is the pressure loss between outer elbow surface tapping and inner elbow surface tapping $[\mathrm{Pa}]$.

To meet this challenge, EDF R\&D has developed a methodology in order to figure out a value for this coefficient $\mathrm{K}$ as relevant as possible for a RCS flow measurement in terms of exactness and uncertainty. This methodology mixes real process data, CFD simulations data and experimental ones. The latter has been partly investigated on EVEREST test bench. The main purpose of these tests were to compare some CFD results obtained with Code_Saturne ${ }^{\mathrm{a}}$ with experimental elbow pressure loss data [8].

This comparisons required a $1 / 4$ scale model of pipe configuration at the outlet of a NPP steam generator, as detailed in figure 7. Steam generator outlet box has been built and installed in the EVEREST test section. Therefore, pipes configurations from this outlet water box up to the U-loop of a NPP RCS loop has also been built. The first device of this configuration was the $40^{\circ}$ elbow.
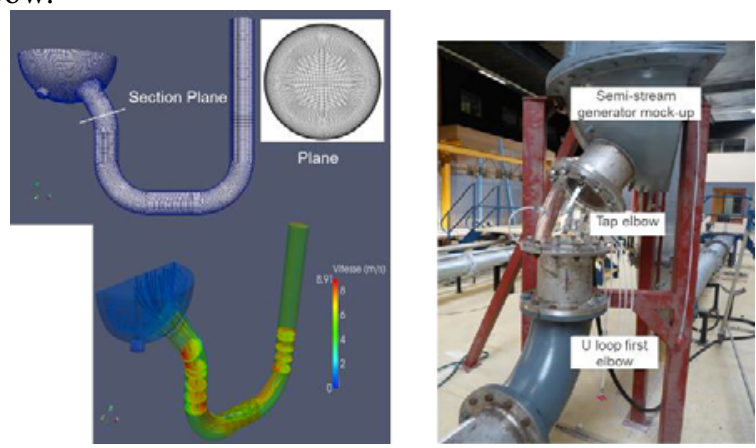

Fig. 7. EVEREST $1 / 4$ scale model (CFD calculations on the left, experimental configuration on the right).

Experiments have been performed with a flow rate range which went from $391 \mathrm{~m}^{3} \cdot \mathrm{h}^{-1}$ up to $1057 \mathrm{~m}^{3} \cdot \mathrm{h}^{-1}$. Uniform and non-uniform velocity profile at the inlet of the water box have been also generated in order to investigate its influence on pressure loss in $40^{\circ}$ elbow.

Testing metrological behavior of a flowmeter on EVEREST loop in the same configuration than its current industrial installation have been performed for many years. However, this particular experiment was one of the first tests campaign with a detailed comparison between CFD results and experimental data obtained on EVEREST loop. This comparison was well enough to generate some other similar studies.

\section{Flow metering assessment: mixing CFD and experiments}

Since 2014, EDF R\&D have performed several comparisons between CFD and experimental data based on EVEREST tests. Main scientific subjects were orifice

${ }^{a}$ http://code-saturne.org 
plate flow metering accuracy [9] [10]. These studies aimed at calculating an orifice plate discharge coefficient with numerical simulations only. This work pointed out the need to increase the overall knowledge of main CFD uncertainties sources and to establish a validated uncertainty propagation method.

Test data obviously have to be accurate as well which entails an appropriate experimental approach. Thus, for orifice plate, this implies to be able to experimentally separate the flow metering influence quantities (downstream straight lengths of pipe, pipe circularity, pressure tappings angular position, pipe roughness, ...) in order to identify precisely experimental uncertainty sources. This identification is the key to perform relevant CFD and tests comparisons. It will be the first step towards using numerical simulations for a quantitative characterization of flow meters metrological performance.

\section{Evolution of EVEREST loop}

In the last twenty years, flow meters performance has been continuously improved by suppliers. In the same time, the required level of accuracy in industrial flow measuring systems have tremendously increased due to economic cost-effectiveness.

Flow meters metrological assessment tests need to be upgraded in order to remain relevant. EDF R\&D has come to the conclusion that, improving flow meters accuracy investigations requires a comprehensive velocity profile understanding. Upgrading the EVEREST test bench has therefore become mandatory.

This objective led EDF R\&D to the idea of redesigning the current EVEREST loop. Overall EVEREST flow metering uncertainty will also be upgraded by using Coriolis meters for flow reference. This feature will allow EDF R\&D to seriously consider having a reference volume flow uncertainty of $0.2 \%$ from $30 \mathrm{~m}^{3} \cdot \mathrm{h}^{-1}$ up to $1100 \mathrm{~m}^{3} \cdot \mathrm{h}^{-1}$.

Moreover, in a near future, EVEREST will be able to provide not only a flow metering reference but also a flow profile reference for several industrial pipe configurations. This purpose will be achieved thanks to Laser Doppler Velocimetry (LDV) and Particle Image Velocimetry (PIV) systems which will be implemented on the new EVEREST loop. Specific flow meters metrological behavior can thus be assessed with well known velocity profiles. Knowing this main influence factor can lead to devices installation optimization and in-situ flow measurement corrections which can lower industrial flow meters uncertainties.

Velocimetry data will also allow EDF R\&D to improve CFD and experimental comparisons on industrial pipe flow configurations by increasing the number of physical parameters which have to be investigated.

\section{Conclusion}

For twenty years, EVEREST loop has been a tremendous tool to increase flow metering influence quantities knowledge. This allowed EDF R\&D to identify the global metrological behavior of innovative flow meters or to assess usual flow meters uncertainties under semi-industrial yet realistic installation configurations.

In the future, the next EVEREST loop will strengthen this feature and leads to accurate flow metering uncertainty calculations thanks to comprehensive velocity profile understanding.

\section{References}

1. C. Barbe, "BOUCLE EVEREST 2.0 Caractérisation des mesures de débits références", EDF R\&D, (2015)

2. Measurement of fluid flow by means of pressure differential devices inserted in circular-cross section conduits running full, Part 1: General principles and requirements, ISO 5167-1 (2003)

3. Measurement of fluid flow by means of pressure differential devices inserted in circular-cross section conduits running full, Part 2: Orifice plates, ISO 5167-2 (2003)

4. J. Veau, L. Ulpat, "Mesure de débit par ultrasons sur une tuyauterie en composite dans une centrale nucléaire", 15th International Congress of Metrology Proc. (2011)

5. B. Kadir, "Mesure de débit par ultrasons - Mesure en conduite pleine - Mesure en conduite pleine", r2265, Techniques de l'ingénieur, (2012)

6. J. Veau, O. Piedfer, "Retour d'expérience d'une mesure de débit par diaphragme à EDF", 15th International Congress of Metrology Proc. (2011)

7. O. Deneux, J.M. Favennec, J. Veau, J. Antunes, O. Piedfer, "Using CFD for metrology prediction in flowmetering: RCS flow measurement with elbow taps", ASME 2013 Power Conference Proc. (2013)

8. O. Deneux, M. Arenas, "CFD and metrology in flowmetering: RCS flow measurement with elbow taps and its uncertainty", 16th International Congress of Metrology Proc. (2013)

9. S. Benhamadouche, W.J. Malouf, M. Arenas, "Effects of meshing and RANS turbulence modelling on the numerical prediction of a flow through a square edged orifice in a round pipe", IHAR 2015, (2015)

10. N. Lancial, M. Arenas, H. Gamel, N. Dessachy, E. Thibert, J. Veau, "Pressure loss prediction by numerical simulations through a square-edged orifice in a round pipe", FLOMEKO (2016) 